\title{
Decência imperial, silêncio republicano \\ normas e gestualidades da leitura em regimentos e estatutos de bibliotecas (1821-1918)*
}

\section{Imperial decency, Republican silence norms and forms of reading in Brazilian libraries}

\author{
Cláudio denipoti \\ Universidade Estadual de Ponta Grossa/PR \\ Universidade Tuiuti do Paraná \\ Rua J osé Nicco, 179 - Mossunguê -Curitiba -PR - CEP 81.200-300 \\ denipoti@ig.com.br
}

\begin{abstract}
RESUMO Este estudo se refere a algumas bibliotecas brasileiras, localizadas no Rio de Janeiro e no Paraná, durante a segunda metade do século XIX e as primeiras três décadas do século XX. Neste tocante, podemos pensar na instituição e manutenção destas bibliotecas no Brasil como forma de obtermos acesso a diferentes padrões culturais pelo estudo sistemático da História da Leitura. Algumas dessas bibliotecas apresentam conjuntos de regras de comportamento que, ao olhar contemporâneo, causam estranhamento. Certas proibições ajudam a definir universos representativos em torno do livro e da biblioteca, ao passo que as prescrições de comportamento, vestimenta e uso das bibliotecas nos falam sobre as representações civilizatórias e moralizantes da parcela da sociedade brasileira responsável pela criação e manutenção dessas bibliotecas. Essa reflexão pode auxiliar o historiador a compreender melhor práticas de leitura no passado.
\end{abstract}

Artigo recebido em:02/08/2006. Aprovado em: 29/05/2007.

(O autor agradece a atenta revisão feita por Marília Mezzomo Rodrigues e Viviane Baggio, da Grifo Nosso) 
Palavras-chave bibliotecas brasileiras, História da Leitura, História Cultural

ABSTRACT This text studies some Brazilian libraries of the late $19^{\text {th }}$ and early $20^{\text {th }}$ Centuries. It tries to see them trhough their own documents, particularly codes and rules of conduct and behaviour - as a way to assess different cultural patterns. In order to do so, it will use the tools of cultural history, particularly those related to the history of the printed word and history of reading. Some of these libraries had sets of rules which, to the modern eye, would seem strange. A number of prohibitions hel to define representative universes around the book and the library, while use, behaviour and dress codes tell us about how civilization and moral were represented by that part of Brazilian society responsible for creating and keeping these institutions. This anaysis can help historians to better understand reading practices in the past.

Key words Brazilian libraries, History of Reading, Cultural History

A história da palavra impressa proporcionou diversos desdobramentos historiográficos conexos aos estudos da leitura no passado, como a história da alfabetização, do comércio e circulação de livros, da formação de bibliotecas, das relações historiográficas entre o historiador e suas leituras, etc. Se tomarmos, por exemplo, o caso da Grécia Antiga, veremos que a leitura era designada por palavras que significavam tanto "o ato de reconhecer" quanto "falar". Assim, "mesmo o leitor solitário (...) não [era] silencioso: ele provavelmente [lia] à meia voz, o que [reduzia] as distâncias entre a leitura individual e a leitura coletiva. Jamais se [lia] unicamente com os olhos; mesmo nas bibliotecas, onde o ruído deveria ser insuportável. Mesmo quando se [estava] completamente só, como vemos na comédia quando aquele que recebia uma carta, a [lia] alto não somente porque [era] necessário informar o público, mas também porque [era] o costume". ${ }^{1}$

Há, porém, um grande fosso entre ser capaz de reconhecer sinais alfabéticos e ler livros ou opúsculos mais ou menos longos. E essa capacidade tem uma ligação íntima com a disponibilidade de material de leitura em uma dada sociedade. No caso da leitura na Antiguidade, ainda que os textos fossem objetos de "circulação limitada", havia uma crescente

1 CANFORA, Luciano. Lire à Athènes et à Rome. Annales E.S.C., v. 44, n.4, juillet/août 1989, p.927. 
preocupação com a formação de bibliotecas - como a de Alexandria² ou a biblioteca pública idealizada por Júlio César em oposição às bibliotecas romanas, cujo acesso era basicamente restrito aos proprietários e seus amigos próximos. ${ }^{3}$

Aqui, aponta-se um dos mais instigantes campos de estudo na história da leitura: a formação e a manutenção de bibliotecas, principalmente se considerarmos, juntamente com Roger Chartier, que "por meio de figuras diversas, o sonho de uma biblioteca que reúna todos os saberes acumulados, todos os livros jamais escritos, atravessou a história da civilização ocidental" ${ }^{4}$ É necessária, contudo, uma ressalva: embora não se possa pensar em uma biblioteca universal e atemporal, certas construções mentais têm traços de similitude em recortes diacrônicos. Esse certamente é o caso das sucessivas reivindicações feitas à herança de Alexandria ou Pérgamo como responsáveis pela criação de novas bibliotecas. Apesar disso, em outros momentos da história, a constituição desses espaços teve características diferenciadas. Se pensarmos nos conventos medievais ou nas grandes bibliotecas do século XVII, teremos dois universos intelectuais distintos - o primeiro, tomista; o segundo, humanista - com o fator comum de que a palavra escrita tinha um valor crucial, qual seja, o destino das idéias estava intimamente ligado "à precariedade da página escrita" . ${ }^{5}$ No caso da Itália do início do século XVII, as grandes bibliotecas, como a Ambrosiana de Milão, a Vaticana e a do Colégio Romano, serviam "como instrumento de monopólio intelectual (...) [e] exprimiam a força e o prestígio da cultura humanística e teológica tradicional que forjava novos instrumentos de erudição e exegese: as armas mais modernas para sustentar em todos os fronts intelectuais o esforço da reforma católica e a luta religiosa". ${ }^{6}$

Contudo, ao mesmo tempo em que serviam como "pontos fortes da cultura teológica e humanista", eram também o instrumento por excelência para a formação de novas idéias. Assim, à riqueza das grandes bibliotecas do período correspondiam a perseguição e a ocultação da palavra escrita considerada perigosa. Através da constante vigilância (buscando livros novos com viajantes e correios que chegavam à cidade, por exemplo) o Santo Ofício, auxiliado pela Congregação do Índex, tentava controlar a circulação de livros. Seu sucesso era relativo, se considerarmos a ampla circulação que livros proibidos tiveram, principalmente na Itália. Pensemos nas obras

2 CANFORA, Luciano. A biblioteca desaparecida: histórias da biblioteca de Alexandria. São Paulo: Companhia das Letras, 1989.

BATTLES, Matthew. A conturbada história das bibliotecas. São Paulo: Planeta do Brasil, 2003, p.52.

CHARTIER, Roger. Culture écrite et société; l'ordre des livres (XIVe -XVIII' siécle). Paris: Albin Michel, 1996, p.107.

REDONDI, Pietro. Galileu herétic o. São Paulo: Companhia das Letras, 1991, p.91-92.

REDONDI, Galileu herético, p.91. 
proibidas (inclusive um exemplar do Decameron) que o moleiro estudado por Carlo Ginzburg lera antes de ser processado pela Inquisição. ${ }^{7}$

Mesmo com essas restrições, as bibliotecas de então possuíam diversas obras que freqüentemente chocavam-se com os interesses da Igreja Católica tridentina. Se os jesuítas "cobriam o mapa da Europa com bibliotecas muito atualizadas" - nas quais, inspirados pela Biblioteca Vaticana, modelavam uma súmula do saber (a ratio studiorum) -, os leigos, reunidos em academias como a dos Lincei - que incluía Galileu Galilei - também aspiravam a instituição de bibliotecas científicas por várias cidades na Itália. Responsáveis pela renovação do pensamento que a obra de Galileu representava, inspiravam suas bibliotecas na do mentor daquela academia, o príncipe Federico Cesi. Intelectual renascentista menor, tinha características extraordinárias de organização e finanças que Ihe proporcionaram a possibilidade de realizar aquilo que "todos, de Bacon a Campanella, sonhavam": criar academias, bibliotecas e edições - como as das obras de Galileu. ${ }^{8}$

Mantendo o ritmo das mudanças provocadas pelo humanismo renascentista, os séculos XVII e XVIII viram uma ampliação e alteração acerca do sentido da palavra "biblioteca", pois ela passou a ser pensada, simultaneamente, como a coleção de livros, o catálogo desta coleção ou, ainda, as compilações de textos que, juntamente com as enciclopédias e os dicionários, constituíam "uma das principais formas dos grandes empreendimentos editoriais do século XVIII"; principalmente na forma de uma das diversas bibliotecas universais que pretendiam, como no L'An 2440, de Louis Sebastien Mercier, resumir o conhecimento em uns poucos volumes sadios e palatáveis à maioria da população. ${ }^{9}$

Sem pretender apontar permanências onde se pode identificar rupturas estruturais, relativas tanto ao significado do livro como às formas da leitura no passado, a começar pela invenção da imprensa, chegando à passagem para uma leitura silenciosa, privada e íntima, ${ }^{10}$ verificamos que as bibliotecas criadas ao longo do século XIX recorriam às definições de si próprias que mantivessem uma ligação contínua com o passado ocidental e continuavam o debate sobre sua própria universalidade. Inseridas na noção de progresso da humanidade, foram pensadas tanto como ferramentas quanto como índice civilizacional, criadas para ritualizar e instituir esse mesmo progresso, ${ }^{11} \mathrm{em}$ geral, segundo preceitos universalizantes. Isso fica evidente nos projetos de criação, organização ou reformulação de bibliotecas nacionais feitos naquele século, como a Biblioteca Britânica ou a Biblioteca Nacional

7 GINZBURG, Carlo. O queijo e os vermes: o cotidiano e as idéias de um moleiro perseguido pela Inquisição. São Paulo: Companhia das Letras, 1987, p.114.

8 REDONDI, Galileu herético, p.94.

9 CHARTIER, Culture écrite, p.111-12.

10 CHARTIER, Culture écrite, p.112.

11 DENIPOTI, Cláudio. Templos do progresso: instituições de leitura no Brasil oitocentista. Locus, Juiz de Fora, v.8, n.2, p.95-106, 2002 
da França. ${ }^{12}$ Similarmente, os clubes de leitura tiveram um importante papel na difusão de idéias por toda a Europa dos séculos XVIII e XIX, facilitando a um maior número de leitores o acesso a maiores quantidades de obras. ${ }^{13}$

As bibliotecas têm sido pensadas e estudadas principalmente a partir de sua carga simbólica e "como um bom símbolo, as bibliotecas sempre deram muito o que falar e pensar e valem, por si sós, uma boa viagem". ${ }^{14}$ Assim, e como parte de processos culturais maiores, as bibliotecas brasileiras oferecem rico material de estudo a historiadores voltados ao universo da leitura. Nesse sentido, busca-se aqui perseguir tais questões em um objeto de estudo mais específico, qual seja, bibliotecas da segunda metade do século XIX e das primeiras décadas do século XX. Deve-se manter em mente que existem diferenças óbvias ligadas à equação tempo/espaço ao relacionarmos os trabalhos mencionados acima com a situação específica aqui estudada. Contudo, é possível pensar na instituição e na manutenção de bibliotecas no Brasil como forma de obter o acesso a diferentes padrões culturais, através do estudo sistemático da história da leitura.

Circunscrevendo o objeto, analisamos a documentação de bibliotecas criadas no Brasil a partir da segunda metade do século XIX, em função da existência de corpus documentais acessíveis, muitas vezes compostos por documentos soltos, como catálogos, estatutos ou regimentos. Isso se deve pela falha na guarda da documentação administrativa da maior parte dessas instituições e, também, pela dificuldade de acesso aos documentos, quando eles de fato existem.

Nesse sentido, as instituições selecionadas são meramente representativas do conjunto das bibliotecas brasileiras do período, sobre as quais foi possível encontrar a documentação indicativa das questões que se buscou compreender, quais sejam, aquelas relativas às formas de comportamento gestual dentro das bibliotecas, em particular em torno da idéia de "decência".

A documentação forneceu a seleção das instituições, portanto. Em primeiro lugar, e em função de estudos anteriores mais detalhados,,$^{15} \mathrm{a}$ Biblioteca Pública do Paraná, através dos regimentos de $1858^{16}$ e $1886 .{ }^{17}$ Complementarmente, as bibliotecas cariocas da Sociedade Litteraria do

12 BATTLES, A conturbada história das bibliotecas, p.120-56.

13 Ver: DARNTON, Robert. Edição e sedição: o universo da literatura clandestina no século XVIII. São Paulo: Companhia das Letras, 1992. Para os clubes de leitura no Brasil Império, SCHAPOCHNIK, Nelson. Contextos de leitura no Rio de Janeiro do Século XIX: salões, gabinetes literários e bibliotecas. In: BRESCIANI, Maria Stella. Imagens da cidade: séculos XIX e XX. São Paulo: ANPUH/SP; Marco Zero; Fapesp, 1994, p.147-162.

14 SCHWARCZ, Lilia Moritz et alli. A longa viagem da biblioteca dos reis: do terremoto de Lisboa à Independência do Brasil. São Paulo: Companhia das Letras, 2002, p.35.

15 DENIPOTI, Cláudio. Páginas de prazer: a sexualidade através da leitura no início do século. Campinas: Ed.Unicamp, 1999; DENIPOTI, Cláudio. A sedução da leitura: livros, leitores e história cultural - Paraná, 1880-1930. Curitiba: UFPR, 1998. (Tese, Doutorado em História).

16 PARANÁ. Leis e diretrizes (1857-58). REGULAMENTO n. 2, de 23 de abril de 1858

17 REGIMENTO da Bibliotheca Pública do Paraná, 1886. Art.17, §único. Gazeta Paranaense, Curityba, 24 mar. 1886. 
Rio de Janeiro, através dos estatutos de $1843,{ }^{18}$ a Biblioteca da Marinha, por seu catálogo de $1865,{ }^{19}$ a Biblioteca do Exército, por seu regimento de $1881,{ }^{20}$ e o Gabinete Português de Leitura, por seu catálogo de 1858. ${ }^{21}$ Nos limites da periodização encontram-se, no início, a Real Bibliotheca, com o regimento de $1821,{ }^{22}$ e, ao final, bibliotecas do início do século XX, nomeadamente a do Club Litterario de Paranaguá, ${ }^{23}$ por seus estatutos de 1914 e a Biblioteca do Instituto Neo-Pitagórico de Curitiba, por seu regulamento interno, de 1918, com algumas referências eventuais a outras bibliotecas citadas por fontes que não foram produzidas pela própria instituição, como o Almanak Laemmert, entre outros.

A documentação foi elaborada com o intuito de regular as formas pelas quais a parte da sociedade brasileira responsável pela criação dessas instituições deveria lidar com o universo dos livros. Estatutos, catálogos, regimentos e regras são aqui interrogados "a respeito deles mesmos, e não, como de costume, sobre alguma outra coisa (...) também perguntando para quais finalidades eles foram originalmente criados". ${ }^{24}$ Podemos pensar os documentos como instrumentos constitutivos da autonomia de um campo cultural, no sentido pensado por Bourdieu, considerando-se "a extensão até a qual [o campo] consegue impor suas próprias normas e sanções sobre o conjunto dos produtores (...)" ${ }^{25}$ Assim, a própria criação dos documentos (e das bibliotecas que eles freqüentemente instituíam) pode ser pensada também como um "processo de institucionalização necessário para a constituição de um grupo (...) coeso, ou seja, um instrumento para a acumulação de capital simbólico" ${ }^{26}$ De qualquer modo, os documentos em foco foram selecionados por terem sido criados dentro de instituições de leitura, visando regular formas e gestos da leitura, mas de maneira alguma esgotam qualquer universo de pesquisa.

O que se propõe aqui é, portanto, trabalhar com regulamentos, estatutos, regimentos e normas de funcionamento (além de prescrições

18 ESTATUTOS da Sociedade Litteraria do Rio de Janeiro. Typographia Universal de Laemmert. Rua do Lavradio, $\mathrm{n}^{\circ}$ $53,1843$.

19 CATALOGO methodico dos livros existentes na bibliotheca da marinha organizado segundo o systema de Mr. Brunet. RJ, Ti. de Francisco de Paula Brito, 1858. Disponível em: <http://www.unicamp.br/iel/memoria/Acervo/index. htm> (Acesso em: 12 jun. 2003).

20 DECRETO N. 8336 - de 17 de dezembro de 1881 (...). Regulamento para a Bibliotheca do Exercito, a que se refere o decreto desta data. Disponível em: <http://www.unicamp.br/iel/memoria/Acervo/index.htm> (Acesso em: 12 jun. 2003).

21 CATALOGO dos livros do Gabinete Portugues de Leitura no RJ seguido de um supplemento das obras entradas no gabinete depois de começada a impressão. RJ, Typ. Commercial de Fo. de Q. Regadas, Praça da Constituição, MDCCCLVIII. Disponível em: <http://www.unicamp.br/iel/memoria/Acervo/index.htm> (Acesso em: 12 jun. 2003).

22 ESTATUTOS da Real Bibliotheca, mandados ordenar por sua Majestade. Rio de Janeiro: Na Regia Typographia, 1821. Disponível em: <http:/www.unicamp.br/iel/memoria/Acervo/index.htm> (Acesso em: $1^{\circ}$ out. 2001).

23 ESTATUTOS do Club Litterario de Paranaguá. Curityba: Typographia d' "A Republica", 1914.

24 BURKE, Peter; PORTER, Roy. (orgs.) História social da linguagem. São Paulo: Ed.Unesp, 1997, p.19.

25 BOURDIEU, Pierre. The field of cultural production. In: FINLELSTEIN, David; McCLEERY, Alistair. The book history reader. London and New York: Routledge, 2002, p.77-99.

26 BOURDIEU, P. The field of cultural production, p.91. 
anotadas por diretores, bibliotecários e funcionários). Desse universo de fontes, procurar-se-á, além da sua própria produção, observar o conjunto de representações elaboradas sobre a própria idéia de biblioteca como local de transformação civilizadora, idealizada por elites brasileiras voltadas para projetos nacionais, em geral europeizantes. Nesse sentido, interessam tanto as justificativas para a criação das bibliotecas quanto as delimitações de códigos de vestimentas e comportamento dentro dessas instituições, tentando compreender como se estabeleceram "campos de respeito" aos recintos e, por conseguinte, aos livros ali contidos.

\section{Da necessidade de instalação e criação de bibliotecas}

Entre a metade do século XIX e o início do XX, o Brasil viu surgir uma grande quantidade de bibliotecas - promovidas pelo Estado ou pela iniciativa privada -, que nos permitem pensar em categorias mais gerais de construção de um campo definidor de identidade, o qual pode ser compreendido em termos de cultura erudita. Para abarcar esse processo, pensa-se numa cultura voltada, fundamentalmente, para a idéia de civilização ocidental e informada pela noção de progresso. ${ }^{27}$ Nesse contexto, é possível considerar a criação - e manutenção - de bibliotecas para além da idéia da constituição de um campo de cultura erudita, como "ritos de instituição" (ou ritos de consagração ou legitimação). Tais ritos podem ser definidos segundo sua função de naturalização de matrizes civilizatórias arbitrárias, o que significa pensá-los como legitimadores de padrões culturais criados a partir de um determinado foco social (nesse caso, a idéia de civilização ocidental, difundida entre o que poderia ser definido de forma ampla e abrangente como a elite brasileira), que passam a ser compreendidos como naturais (o progresso torna-se o desígnio natural da humanidade, e as bibliotecas, seu signo). Segundo Bourdieu, "neste caso, instituir é consagrar, ou seja, sancionar e santificar um estado de coisas, uma ordem estabelecida, a exemplo precisamente do que faz uma constituição no sentido jurídico do termo". 28

Fosse como parte da tentativa de criar a nacionalidade e a identidade brasileiras, fosse como empenho de afirmação da superioridade de um modelo político sobre seu antecessor (o republicano sobre o monárquico, por exemplo), ou ainda como construção da civilização, as bibliotecas brasileiras do século XIX - e também as européias - foram dotadas de uma

27 BAUMER, Franklin. O pensamento europeu moderno. Lisboa: Edições 70, [s.d.]. 2.v. Existem diversos estudos sobre as formas de concepção do mundo engendradas pela elite brasileira do século XIX. Ver, por exemplo, SCHWARCZ, Lilia Moritz. O espetáculo das raças: cientistas, instituições e questão racial no Brasil, 1870-1930. São Paulo: Companhia das Letras, 1993; e SCHWARCZ, Lilia Moritz. As barbas do imperador: D. Pedro II, um monarca nos trópicos. São Paulo: Companhia das Letras, 1998.

28 BOURDIEU, Pierre. A economia das trocas lingüístic as: o que falar quer dizer. São Paulo: Edusp, 1998, p.98-99. 
aura redentora, verificável na sua documentação - na forma de civilização e como delimitadora dos papéis sociais. Atos de criação, considerados no contexto da predominância de uma idéia de progresso, ${ }^{29}$ podem ser vistos na mudança da função das bibliotecas brasileiras, ao passarem de demonstração barroca de grandeza material - como era a Real Bibliotheca, descrita em 1821 como "alfaia preciosa da coroa de Portugal"30 - para a categoria de instrumentos instauradores de progresso, manifesto mais como capital simbólico que como progresso material de facto.

As bibliotecas deixavam de ser signo de poder pessoal ${ }^{31}$ e tornavam-se instrumentos para a elevação de toda a sociedade à civilização, vistas e criadas como símbolos do progresso e instrumentos de sua obtenção. ${ }^{32}$ Além das motivações alegadas para a concepção e a preservação de bibliotecas, suas formas de "manutenção da ordem" regulamentar podem nos informar sobre o papel simbólico que essas instituições tiveram no passado.

As associações alegóricas acerca da criação de bibliotecas afirmam que os responsáveis por essa criação são impulsionados por aspirações bastante grandiosas, como "[o] desejo de promover o adiantamento das sciencias, das artes, e da industria, de facilitar a instrucção geral", manifestado pelo diretor da Sociedade Litteraria do Rio de Janeiro, no discurso de abertura da primeira Assembléia Geral. ${ }^{33}$ De forma semelhante, a Biblioteca Pública do Paraná (BPPR) teve, quando de sua fundação, "por fim a propagação dos conhecimentos humanos (...) [p]restando gratuitamente aos amigos das lettras meios de estudos proficuos e variados". ${ }^{34}$ Esses ideais, ligados à noção de educação universal eram comumente usados como justificativa ou legitimação para a criação de tais instituições. Não obstante, outros ideais mais práticos - embora devam ser vistos a partir do mesmo conjunto ótico - informavam a necessidade de serem fundadas bibliotecas. Em 1858, a Biblioteca da Marinha ampliou sua ação criando pequenas filiais nos próprios navios. Além de educar, elas deveriam ajudar

29 Entendido aqui como preconizado principalmente por Saint-Simon, em termos de uma idéia de sociedade em contínuo progresso, alternando épocas "orgânicas" e "críticas", amplamente aceita e adotada, ainda que tacitamente ou com variantes sutis entre seus adeptos, por todas as escolas de pensamento posteriores à Revolução Francesa. Ver BAUMER, 0 pensamento europeu moderno. Lisboa: Edições 70, [s.d.], v.1, p.13.

30 alfaia: jóia. ESTATUTOS da Real Bibliotheca..

31 Segundo Lilia Schwarcz, "... a promoção desse tipo de instituição representou, por um lado, questão de prestígio para a realeza, e era paralela ao mecenato que soberanos e nobres empreendiam nas cortes européias. As monarquias se apresentavam a partir de suas livrarias, como se a cultura presente nesses acervos projetasse a própria imagem do soberano...". SCHWARCZ, L et alli. A longa viagem..., p. 71.

32 A Biblioteca Municipal do Império, criada em 1878, tinha por objetivo não ser "aristocrática como se tem por ahi escripto noutras circunstancias e em respeito do nosso primeiro estabelecimento desta espécie, o que nos parece contrario aos reclamos da civilização actual e antinomico com os intuitos gerais de nossa forma de existencia social...". CATÁLOGO da Biblioteca Municipal. Publicação Official. Rio de Janeiro: Typ. Central de Browm e Evaristo, 1878. Disponível em: <http://www.unicamp.br/iel/memoria/Acervo/index.htm> (Acesso: em 9 mai. 2005). Ver também DENIPOTI, C. Templos do progresso, p.101.

33 ESTATUTOS da Sociedade Litteraria do Rio de Janeiro, p.3.

34 PARANÁ. Leis e diretrizes (1857-58). REGULAMENTO nº 2 de 23 de abril de 1858, art. 2 
os oficiais a vencer a preguiça e evitar que os marinheiros se aplicassem a formas de entretenimento repreensíveis.

Já o amor dos livros se espalha pelos navios com a installação das Bibliothecas Parciaes e é de presumir que o nosso marinheiro, lendo romances maritimos, viagens e episodios navaes, va insensivelmente trocando por esta distração outras que a disciplina nem sempre consegue reprimir. $\mathrm{O}$ oficial possue agora os meios de aprofundar ao [sic] ramos prediletos de sua profissão, e, tendo ao seu alcance tantos livros bons, vencerá a natural indolencia do espirito para os estudos serios, sem que a desculpe com a impossibilidade de obter uma bibliotheca. ${ }^{35}$

No caso da Biblioteca do Exército, essa tendência foi expressa de forma mais completa na apresentação feita no Catálogo, de 1885: "com effeito, as vezes que alli estive causou-me certa impressão ver na sala dos soldados muitos delles lendo tranquilamente durante as horas que lhes são concedidas para descanço, empregando assim melhor o tempo do que nas tabernas ou em outros pontos ${ }^{36}$

Na mesma vertente da criação de ocupação "sadia" e "decente" do tempo, o Clube Litterario de Paranaguá se definia, em 1914, como uma "organização litteraria e recreativa", cujos principais fins eram tanto educativos quanto de entretenimento, e seus estatutos previam as obrigações de:

a) manter uma bibliotheca em condições de facilitar a leitura de obras litterarias e scientificas, de jornaes, revistas e outras publicações. b) manter aos socios, toda a especie de diversões, como sejam: Dança, musica, leitura, conferencia, jogos licitos e outros, procurar por meio de correspondencia continua, a approximação de associações congeneres deste e de outros Estados, mantendo permuta de livros, jornaes, revistas e publicações. ${ }^{37}$

Reunindo essas características, as bibliotecas, juntamente com outras instituições concebidas no mesmo período, como museus, teatros, etc., exerciam sua influência nos projetos civilizadores das elites nacionais, que pretendiam demonstrar compromisso com ideais de inspiração inquestiona-

35 CATALOGO methodico dos livros existentes na bibliotheca da marinha organizado segundo o systema de Mr. Brunet. RJ, Ti. de Francisco de Paula Brito, 1858, p. 1. Disponível em: < http://www.unicamp.br/iel/memoria/Acervo/index.htm> (Acesso em: 12 jun. 2003).

36 CATÁLOGO da Bibliotheca do Exercito Brazileiro precedido de seu regulamento e leis que lhe dizem respeito acompanhado de um índice alphabetico dos autores organizado pelo bibliotecário Joaquim Alves da Costa Mattos, official da Ordem da Rosa, cavalleiro da de Christo, condecorado com as medalhas de mentor militar das Ca[??], do Estado oriental do Uruguay de 1864 - 1865, RJ, Imprensa Nacional, 1885. p. VII. Disponível em: < http://www. unicamp.br/iel/memoria/Acervo/index.htm> (Acesso em: 12 jun. 2003).

37 ESTATUTOS do Club Litterario de Paranaguá, p.3. 
velmente européia. ${ }^{38}$ Criar bibliotecas e dotá-las de regras de funcionamento - com delimitações claras sobre quem teria acesso aos livros e como deveria ser o comportamento das pessoas no ambiente em que esses livros eram guardados - se tornava uma premissa do acesso a códigos de comportamento "civil" - ao menos, dentro dessas instituições.

\section{Do público e dos comportamentos}

Ao serem criadas as bibliotecas, definia-se também quem elas deveriam atender e como as pessoas deveriam ali se comportar. Na categoria de bibliotecas públicas, que seriam (ao menos em tese) abertas a todos, algumas restrições eram impostas. No caso da Bibliotheca Nacional e Pública da Corte (depois Bibliotheca Nacional da Corte), por exemplo, seriam atendidas "todas as pessoas que se apresent[ass]em devidamente vestidas" ou "decentemente vestidas", conforme o aviso repetido nas páginas do Almanack Laemmert durante todo o período em que o periódico foi analisado, entre 1844 e 1889. ${ }^{39}$ A mesma regra era aplicada pela Bibliotheca da Câmara Municipal do Município Neutro, que era "franca às pessoas decentemente vestidas". ${ }^{40}$ No caso da BPPR, embora em 1858 oferecesse, livremente, a "todas as pessoas a leitura ou exame de alguma obra", ${ }^{41} \mathrm{em} 1886$, o novo regulamento da instituição, outorgado com o intuito de reformulá-la, previa que "as pessoas que frequentarem a Bibliotheca deverão apresentar-se vestidas com decência...." . ${ }^{42}$ Fazendo coro a essas recomendações, a Biblioteca do Exército prescrevia que "[a]s pessoas que freqüentarem a bibliotheca deverão apresentar-se decentemente vestidas, bem como guardar todo decoro e silencio indispensáveis em um estabelecimento dessa ordem";43 enquanto o Gabinete Português de Leitura determinava que os leitores deveriam guardar sempre "absoluto silencio, e a decencia que costuma haver em estabelecimentos de semelhante natureza". ${ }^{44}$

Ao longo do século XIX, em conjunção com seus diversos sinônimos (decoro, dignidade, conveniência, modéstia, pudor, reserva, recato...) o termo "decência" foi freqüentemente associado à aparência. No dicionário de José Ignacio Roquette (1848), decente é, além de "conforme a honestidade",

38 Ver: MOLINA, Ana Heloísa. A influência das artes na civilização: Eliseu D’Angelo Visconti e a modernidade na Primeira República. Curitiba: UFPR, 2004. (Tese, Doutorado em História).

39 ALMANAK administrativo, mercantil e industrial do Rio de Janeiro para o anno bissexto de 1844. Rio de Janeiro: Casa de Eduardo e Henrique Laemmert, 1843, p.72; ALMANAK administrativo, mercantil e industrial da Corte e Província do Rio de Janeiro para o anno de 1868. Rio de Janeiro: E. \& H. Laemmert, 1868, p.91; ALMANAK LAEMMERT. Rio de Janeiro: Laemmert \& C., 1889, p.1588.

40 ALMANACK LAEMMERT, 1884, p.1250.

41 PARANÁ. Leis e diretrizes (1857-58), Art. 15.

42 REGIMENTO da Bibliotheca Pública do Paraná, 1886, art.17, p.2-3.

43 CATÁLOGO da Bibliotheca do Exercito Brazileiro, art.12, p.X.

44 CATÁLOGO dos livros do Gabinete Portugues de Leitura, art.16, p.V. 
"adornado sem luxo, com asseio e limpeza". 45 Já para Francisco Solano Constancio (1854), decência ou decoro era a "conveniencia no traje, nas maneiras, nas expressões, honestidade nos vestidos, no proceder, nitidez, elegancia singela...", ao mesmo tempo que um definidor social, pois seria "o que convem a cada hum, ao seu estado, condições, posses...". ${ }^{46} \mathrm{O}$ carioca Antonio de Moraes da Silva, em seu dicionário de 1858, seguiu essa concepção, definindo decência como "... [r]ecolhimento, honestidade no exterior, [t]ractamento de vestidos, e familia conforme ao estado", fazendo uma distinção entre decência e decoro.

\begin{abstract}
A decência refere-se á honestidade moral, regula o exterior segundo os bons costumes. O decoro refere-se á honestidade civil, elle regula as nossas acções segundo os costumes e usos da sociedade. (...) Uma senhora veste-se com decência, quando traja sem immodestia; com decoro, quando se veste segundo sua condição (...). A decência em geral é uma e mesma cousa para todos; o decoro varía segundo o sexo, idade, estado, e condição das pessoas, porque o que assenta bem em um homem, em um moço, em um militar, não está bem em uma senhora, em um velho, em um magistrado. (...) Guarda-se a decência, respeita-se o decoro... ${ }^{47}$
\end{abstract}

As formas de entendimento da decência e do decoro foram detalhadas em alguns regimentos, principalmente em suas proibições. Além das restrições já elencadas, a BPPR proibia, rigorosamente, fumar no estabelecimento, bem como "conservar-se o chapéo na cabeça". ${ }^{48}$ O regimento da Biblioteca do Instituto Neo-Pitagórico de Curitiba estabelecia múltiplas interdições, que podem ser entendidas como definidoras de comportamentos decentes, esperados dos leitores.

Art. 2. Não é permitido:

cuspir no pavimento;

fumar, comer ou beber no interior do edifício;

palestrar, altercar, discutir;

toccar nos livros das estantes;

annotar os livros, assignalar as paginas ou marcar as folhas;

estar folheando o volume, pedido ao bibliotecario, por mero passa-tempo... ${ }^{49}$

As regras relativas à decência, repetidas e reiteradas, excluíam grande parte da população brasileira do século XIX, que não podia preencher os

45 ROQUETTE, José Ignacio; FONSECA, Jose da. Diccionario da língua portuguesa. Paris: Guillard Aillaud, 1848, p.330.

46 CONSTANCIO, Francisco Solano. Novo diccionario critico e etymologico da lingua portuguesa. Paris: Angelo Francisco Carneiro Filho Editor, 1854, p.345.

47 SILVA, Antonio de Moraes. Diccionario da língua portugueza. Lisboa: Typographia de Antonio José da Rocha, 1858 p.601-602.

48 SILVA. Diccionario da língua portugueza, p.602.

49 REGULAMENTO interno da Bibliotheca do Instituto Neo-Pithagorico. Myrtho e Acacia III (1 e 2), primavera e estio, 1918, p.126-7. 
requisitos da "decência" de trajes, por ser pobre demais, por um lado, ou por ser escrava, por outro. De qualquer modo, parcela majoritária da população não estava incluída em projetos civilizadores pelas condições em que se apresentavam ao olhar público, mas seria o material sobre o qual a civilização deveria agir. Vale a pena notar a ausência de qualquer referência à escravidão nos documentos analisados, demonstrando o que Lilia Moritz Schwarcz caracterizou como a auto-imagem nacional do Segundo Império, a ser perpetuada como "européia mas 'romanticamente nacional', tradicional mas ligeiramente moderna, rica, sábia, cristã, catequizadora, vitoriosa, conquistadora. Escravocrata? Nem pensar...". ${ }^{50}$

Outro tipo de biblioteca restringia o acesso a seus acervos por conta de pressupostos profissionais, como, por exemplo, as bibliotecas militares, que eram geralmente corporativas, embora permitissem a eventual consulta de "paisanos". Assim, a Biblioteca da Marinha estabelecia que: "é permittido aos officiaes Generaes dArmada, e aos chefes dos differentes departamentos da repartição da marinha requisitarem, por officios dirigidos ao official encarregado da Bibliotheca, os livros que quizerem ler fora dela. A excepção desses á ninguém mais se emprestará livro algum fora da Bibliotheca, sem ordem superior. ${ }^{51}$

Da mesma forma, a Biblioteca do Exército era "destinada especialmente aos officiaes e praças de pret [sic]" ${ }^{2}$ mas permitia, como a sua congênere da Marinha, que as obras fossem consultadas in loco por "todos os empregados do ministerio da Guerra, bem como ao publico em geral" . ${ }^{53}$

Já as bibliotecas particulares, como o Gabinete Português de Leitura e a Bibliotheca Fluminense restringiam o acesso a seus associados "subscritores", que pagavam taxas de $12 \$ r$ a a ano para consultar e emprestar as obras contidas nesses acervos. Porém, enquanto o Gabinete aceitava "subscritores de qualquer nacionalidade e sexo", desde 1854, ${ }^{44}$ a Bibliotheca Fluminense limitava-se "só para nacionaes", ${ }^{55} \mathrm{em} 1848$. Menos de uma década depois, no entanto, essa mesma instituição aboliu suas restrições, aceitando "(...) assignaturas de qualquer nação e sexo (...)",56 indicando

50 SCHWARCZ, L. As barbas do imperador, p.187. Ver também: PENA, Eduardo Spiller. Pagens da casa imperial: jurisconsultos, escravidão e a lei de 1871. Campinas: Ed. da Unicamp, 2001, particularmente o primeiro capítulo, onde há menção à ação de Teixeira de Freitas, que se recusa sistematicamente a incluir as leis relativas aos escravos nos códigos legislativos, em nome de um progresso inevitável que apagaria as marcas da escravidão no Brasil.

51 CATALOGO methodico dos livros existentes na bibliotheca da marinha, p.2; ALMANAQUE Administrativo, mercantil e industrial da corte e província do Rio de Janeiro para o anno de 1865. Rio de Janeiro: Eduardo \& Henrique Laemmert, 1865, p.222.

52 CATÁLOGO da Bibliotheca do Exercito Brazileiro, p.V.

53 DECRETO N. 8336 - de 17 de dezembro de 1881 (...) Regulamento para a Bibliotheca do Exercito, a que se refere o decreto desta data. Art. $1^{\circ}$, p. IX. Disponível em: <http://www.unicamp.br/iel/memoria/Acervo/index.htm> (Acesso em: 12 jun. 2003).

54 ALMANAK administrativo mercantil e industrial da corte e provincia do Rio de Janeiro para o anno de 1854. Rio de Janeiro: Eduardo e Henrique Laemmert, 1854, p.318.

55 ALMANAK administrativo mercantil e industrial da corte e provincia do Rio de Janeiro para o anno bissexto de 1848. Rio de Janeiro: Eduardo e Henrique Laemmert, 1848, p.273.

56 ALMANAK administrativo mercantil e industrial da corte e provincia do Rio de Janeiro para o anno de 1855. Rio de Janeiro: Eduardo e Henrique Laemmert, 1855, p.315-316. 
uma atenuação da xenofobia do período regencial (que ocorria parcialmente em virtude do processo de imigração européia para o Brasil, iniciado nesse período). A Sociedade Litteraria do Rio de Janeiro pressupunha uma assinatura de quinhentos réis mensais, mas detalhava mais claramente quem poderia ser sócio e usufruir da biblioteca.

Art. 3. He mister, para ser sócio, estar no pleno gozo de seus direitos civis, a fim de poder responder por suas produções literarias perante a Lei de imprensa. (...) Art. 4. Para ser sócio he preciso: huma requisição por escrito, assignada por qualquer dos membros da sociedade, dirigida ao Conselho, contendo o nome do proposto, seu emprego e moradia. ${ }^{57}$

A partir dessas definições, podemos caracterizar os prováveis leitores como sendo: 1) letrados ou - no mínimo e por razões óbvias - alfabetizados; 2) decentes, ou seja, aptos a apresentarem-se vestidos "com asseio e limpeza", "conveniência no traje" de acordo com o que "convem a cada hum" - ao acatarmos as definições dos dicionaristas luso-brasileiros do século XIX -; e 3) capazes de arcar com os custos das subscrições (no caso das bibliotecas e clubes particulares).

Com a honrosa exceção das bibliotecas militares, que pretendiam incluir a soldadesca e os marinheiros embarcados no universo de leitores em potencial, as outras instituições demonstrariam trabalhar em plano antes normativo que descritivo, uma vez que os documentos expressam uma "vontade" civilizadora - mesmo levando em conta a especificidade das fontes, normativas por definição. Esses documentos produziram também uma falsa noção de que o império tropical e o seu sucedâneo republicano eram sociedades amplamente letradas ou, pelo menos, amplamente devotadas às letras e ao universo da leitura.

\section{Da consulta aos livros}

Mesmo que o público fosse restrito às camadas letradas da população, ainda assim elas precisavam ser disciplinadas no contato com os livros, já que esses guardavam uma aura de preciosidade onde quer que estivessem armazenados. Esse disciplinamento deveria ser exercido por um corpo específico de funcionários - ou, na maioria dos casos, exclusivamente pelo bibliotecário. A julgarmos pelo regulamento da Bibliotheca Pública de Lisboa (circa 1801), essa preocupação era antiga, já que a eventual sucessora da Biblioteca Real - transportada para o Brasil - previa que os nove "oficiaes bibliográfos" deveriam: "10 instruir o publico dos livros que há nas Salas, e subministrar os que se pedem e recolhê-los a seus lugares depois que se

57 ESTATUTOS da Sociedade litteraria do Rio de Janeiro, [s.p.]. 
lem. $2^{\circ}$ vigiar continuamente as salas para evitar o arroído dos que vem de fora e o mau tratamento dos livros, ou o seu descaminho". 58

Essa disciplina exigia, inicialmente, uma distância entre os leitores e os locais onde os livros ficavam depositados. Em nenhuma das instituições estudadas, os leitores tinham permissão para escolher os livros que desejassem, diretamente das estantes, como é o caso da maioria das bibliotecas brasileiras atuais. Na Bibliotheca Nacional e Pública da Corte, não era "permittido a qualquer pessoa de fóra tirar livro algum das estantes, nem pôl-o; mas dirigir-se aos Empregados que para esse fim estiverem presentes". ${ }^{59} \mathrm{De}$ forma semelhante, na BPPR nenhuma pessoa podia "tirar livros ou outros quaisquer objectos das estantes, e em tão pouco repol-os em seu lugar", sendo também proibido "entrar na Bibliotheca com livros, e ainda mais sahir com elles". 60 Exemplo do distanciamento entre os leitores e as formas de organização das bibliotecas foi dado pelo regimento do Gabinete Português, que proibia "expressamente (...) aos leitores e visitantes (...) mexerem nas estantes; [eles] deverão pedir ao guarda qualquer obra que pretenderem ler ou consultar, e devolver-lha depois, a fim de não transtornar-se a ordem da sua collocação". ${ }^{61}$ No caso da biblioteca pública paranaense, o regimento de 1886 era ainda mais incisivo, proibindo, inclusive, "estar examinando os livros nas estantes", mas abrindo uma exceção semanal "ás quintas feiras de cada semana, em que será consentido esse exame, sempre discreto e pouco demorado". ${ }^{2}$ Essas normas denotam a necessidade de treinamento na organização dos livros nas bibliotecas, ao mesmo tempo em que pressupõem uma aura de "respeito", condizente com as noções de "decência" exigidas dos freqüentadores das instituições - o respeito e a respeitabilidade entendidos como parte intrínseca da "decência" e seus sinônimos. ${ }^{63}$

58 DIAS, L. F. Carvalho. O primeiro regulamento da Biblioteca Nacional. Revista da Biblioteca Nacional de Lisboa, v.1, n.1, p.176, 1981

59 ALMANACK Administrativo, 1843, p.73

60 PARANÁ. Leis e diretrizes (1857-58), arts.17 e 18.

61 CATALOGO dos livros do Gabinete Portugues de Leitura no RJ seguido de um supplemento das obras entradas no gabinete depois de começada a impressão. RJ, Typ. Commercial de F. de ${ }^{\circ} \mathrm{Q}$. Regadas, Praça da Constituição, MDCCCLVIII. art. 15, p. V. Disponível em: < http://www.unicamp.br/iel/memoria/Acervo/index.htm> (Acesso em: 12 jun. 2003).

62 REGIMENTO da Bibliotheca Pública do Paraná, 1886 (Manuscrito), art.51.

63 Segundo o Novo diccionário critico de Francisco Solano Constâncio, decoro é "(...) decencia, conveniencia das palavras, acções, do trajar, e mais exteriormente; honra, acatamento, respeito devido a alguem por sua dignidade, qualidade, sexo, etc...". Respeito, por sua vez, é definido como "(...) attenção, consideração, acatamento, veneração (...) he a attenção ou consideração que se tem ou se dá a alguém ou a alguma cousa. Deferencia denota superioridade reconhecida do caracter e opiniões da pessoa a quem se tributa. Reverencia: he respeito submisso com temor filial. Veneração: he reverencia religiosa, respeito profundo e submisso como a cousas divinas, sagradas. Acatamento, he demonstração de respeito. Deve-se respeito aos superiores, aos talentos, aos direitos; deferencia á idade; reverencia aos pais, mestres; veneração a Deos, a ancião venerável". Antonio Moraes da Silva define respeito como "... a attenção ou consideração que se dá a alguém, ou alguma cousa. Deferência é o respeito que se tem aos sentimentos, desejos, e gostos de qualquer pessoa, preferindo-os aos nossos, por alguma superioridade que julgamos haver nessa pessoa. Reverencia é o respeito com temor filial. Veneração é o respeito profundo e submisso...". CONSTANCIO, F. S. Novo dic cionario critico e etymologico da lingua portuguesa, p.346 e p.850. SILVA, A. de M. Diccionario da língua portugueza, t.II, p.722. 
Todas as regras estabelecidas quanto a formas de comportamento e gestualidade eram reforçadas pela ação dos funcionários - porteiros e bibliotecários em geral -, a quem competia: "fazer a polícia da casa, admoestando, aos que perturbarem a ordem, para que se corrijam, não permitindo de modo algum discussões de qualquer natureza que sejão", ${ }^{64}$ bem como pelos próprios leitores e freqüentadores que, embora alvos das normas, participavam de sua aplicação - nesse sentido, a documentação apresenta uma grande quantidade de exemplos.

No Gabinete Português de Leitura, qualquer contravenção às normas de silêncio, decência e acesso aos livros - comportamento esse que os idealizadores do Gabinete imaginavam ser excepcional, pois "não he de esperar" - seria "admoestado pelo guarda, e reincidindo, (...) excluído da leitura por um mez". ${ }^{65}$ Essas ações assemelham-se às obrigações dos funcionários da Real Bibliotheca, em escala hierárquica desde o prefeito aos serventes, que deviam cuidar "o mais que lhe for possível em evitar toda a desordem, e rumor, e assim também zelará que não se escreva sobre os livros, e que estes se não manchem, maltratem ou extraviem...", fazendo uso, quando necessário, dos serviços "de huma guarda militar como a havia em Lisboa". 66

Ecos do trabalho de patrulha estão presentes nos bilhetes de admoestação escritos por um bibliotecário da BPPR, no início do século XX. Em 1919, por exemplo, ele anota ter advertido duas alunas do primeiro ano da Escola Normal "varias vezes para que se mantem-se [sic] com decencia no recinto da biblioteca".

Poucas instituições permitiam o empréstimo de obras para fora de suas salas de leitura. Mesmo nesses casos, havia regras minuciosas controlando os leitores. No caso do Gabinete Português, era necessário assinar "com o seu nome e firma por extenso no registro para esse fim destinado. Os subscriptores assignarão da mesma forma em outro livro, sucessivamente, sujeitando-se ás disposições deste regulamento, que lhes são applicaveis". ${ }^{67}$

Já na BPPR, a forma de solicitação de livros era prosaica, demonstrando a precariedade dos serviços: "todo aquele que precisar de qualquer livro para leitura ou consulta, deverá fazer seu pedido por escripto num quadradinho de papel ou boletim que o zelador Ihe apresentar. ${ }^{68}$ Prática que, embora não mais constasse nos regulamentos da BPPR, continuou a ser o padrão para a autorização de retirada de livros, geralmente assinados pelo diretor da biblioteca, recomendando ao bibliotecário que entregasse livros.

64 PARANÁ. Leis e diretrizes (1857-58), cap.II, art.12, §6

65 CATALOGO dos livros do Gabinete Portugues de Leitura, art.17.

66 ESTATUTOS da Real Bibliotheca, §XI.

67 ESTATUTOS da Real Bibliotheca, art.19, §V.

68 PARANÁ. Leis e diretrizes (1857-58), cap.II, art.18. 
Quanto a isso, a Biblioteca do Exército permitia somente que os "officiaes generaes do Exército, os chefes das differentes repartições no ministério da Guerra, e os membros da Commissão de melhoramentos de material de guerra" retirassem livros, pelo período de quinze dias (ampliável somente por ordem superior). Os demais freqüentadores, militares ou não, deveriam obedecer ao regulamento, particularmente minucioso quanto aos procedimentos de consulta aos livros.

Art. $13^{\circ}$. Os leitores e visitantes da bibliotheca receberão do porteiro, ao entrar, uma senha numerada, que apresentarão ao ajudante do bibliothecario, e no boletim que por este Ihes for dado inscreverão o numero da senha, o titulo da obra que desejarem consultar, e bem assim a sua assignatura e morada.

Art. $14^{\circ}$. A vista do referido boletim o ajudante do bibliothecario procurará nos catalogos a obra pedida; se esta existir na casa, inscreverá no mesmo boletim as condições precisas para que o guarda a encontre; e se não houver, fará esta declaração por escripto e entragará ao leitor a sua senha numerada, que sera restituida ao porteiro na occasião da sahida. (...)

Art. 16․ Em um só boletim não se poderá requisitar duas obras, nem poderao ser dadas ao leitor a um tempo mais de tres, salvo licença expressa do bibliothecario. Outrossim não será permittido fazer pedidos meia hora antes do encerramento dos trabalhos. ${ }^{69}$

Insistindo na restrição de saída dos livros, no final do período estudado, o Club Litterario de Paranaguá estabelecia, em 1914, que "para fóra do Club só poderão sahir romances, podendo o sócio tel-os em seu poder durante oito dias, contados da data do recebimento. Findo este prazo, e não tendo recolhido o livro ou livros, pagará o importe da obra e mais 15\%", prevendo também que os sócios só poderiam retirar um livro de cada vez. ${ }^{70}$

Essas proibições e regras indicam forte valorização dos objetos de leitura contidos nas bibliotecas, mas, em se tratando de uma sociedade com diferentes formas de hierarquização, havia exceções, consideradas importantes o suficiente para constarem dos códigos de normas. O Gabinete Português dá pistas sobre a presença das mulheres nos ambientes públicos de leitura, quando previu que suas subscritoras (e os "homens que tiverem algum impedimento") não precisariam sair do recôndito doméstico para retirar livros, podendo "assignar em sua casa, para o que o guarda, informado desse motivo pela pessoa interessada, Ihe enviará o mencionado livro de registro pelo continuo ou outra pessoa de sua confiança", ${ }^{71}$ mantendo assim o "decoro", que estabelecia o espaço doméstico como espaço feminino por excelência. ${ }^{72}$

69 CATÁLOGO da Bibliotheca do Exercito Brazileiro, p.X-XI.

70 ESTATUTOS do Club Litterario de Paranaguá, arts. $4^{\circ}$ e $5^{\circ}$, §22.

71 CATALOGO dos livros do Gabinete Portugues, art.19, §V.

72 Ver: DEGLER, Carl. At odds: women and the family in America from the Revolution to the present. Oxford: Oxford University Press, 1981. 
No caso da BPPR, as exceções diziam respeito ao status social do leitor, pois "pessoas de distincção e em viagem" podiam quebrar as regras estabelecidas quanto ao horário de funcionamento e ao exame das obras nas estantes, ${ }^{73}$ fazendo eco ao que os estatutos da Real Bibliotheca previram quando estabeleceram que a biblioteca não deveria ser aberta fora dos horários normais, exceto se "alguma pessoa de concideração dezeje (sic.), e peça que quer ver a bibliotheca mesmo em dia feriado". ${ }^{74}$

Como vimos, em geral as bibliotecas estudadas apresentavam conjuntos de regras bastante específicas quando às formas de acesso aos livros, porém, em alguns casos, excediam a mera regulamentação da leitura para incidir sobre os comportamentos dos usuários nos espaços de leitura. Se pensarmos que a grande revolução ocidental no que diz respeito à leitura foi a passagem de uma leitura feita à meia voz para a leitura silenciosa, ${ }^{75}$ ocorrida ao longo dos séculos XVII e XVIII, é fácil compreender por que a proverbial exigência de silêncio quanto à leitura estava presente em quase todos os documentos pesquisados.

Porém, nas tipologias possíveis sobre a história do silêncio, podemos pensar o silêncio nas bibliotecas como sinal de respeito (da mesma forma que crianças deveriam calar-se durante uma conversação de adultos) e também reverência religiosa, compreendida como "um misto de respeito por uma divindade, uma técnica para abrir o ouvido interior; e um sentido de inadequação de palavras para descrever as realidades espirituais", ${ }^{76}$ todas elas características que podem, em variados graus, ser atribuídas ao silêncio face ao livro e à leitura. Isso fica ainda mais patente quanto observamos que as exigências de silêncio vinham, geralmente, acompanhadas de apelos à "decência" e ao "decoro".

\section{Considerações finais}

A noção de decoro evidenciada pelas fontes ajuda a compreender as tentativas de substituir divertimentos (e práticas sociais) de origem popular - mas provavelmente disseminados por todos os estratos sociais - pela ilustração através da leitura. Silêncio, roupas adequadas, comportamentos sóbrios e reverência aos livros eram objetivos a serem atingidos pela sociedade, e as bibliotecas, seus idealizadores e regras ajudavam a criar os ritos necessários para a instauração e a perpetuação desses objetivos.

Esses locais privilegiados da leitura ocupavam, assim, posição de destaque na vida das pessoas, tanto daquelas envolvidas com as insti-

73 REGIMENTO da Bibliotheca Pública do Paraná, 1886, art.51, § único; art.16, §4

74 ESTATUTOS da Real Bibliotheca, §XXVII.

75 CHARTIER, R. Culture écrite et societé.

76 BURKE, Peter. Anotações para uma história social do silêncio no início da Europa Moderna. In: A arte da conversação. São Paulo: Ed. da Unesp, 1995, p.166. 
tuições que mantinham esses locais, quanto de outras, interessadas no lazer, na informação ou na ritualização civilizatória que tais espaços podiam proporcionar.

O conjunto de normas revela que o universo da leitura em bibliotecas era regido simultaneamente por um endeusamento dos livros e das bibliotecas e pelas tentativas civilizadoras - das quais essas instituições eram tanto fruto quanto índice. Tinham como objetivo claro a leitura, ou a possibilidade da leitura, das obras contidas em acervos e coleções. Clubes, escolas e bibliotecas manifestavam em suas organizações a necessidade de um local adequado para guarda e consulta de livros, local esse freqüentemente dotado de uma aura sagrada ou semi-sagrada, passível de ser venerada (outra variável contida nos conceitos de decência e de respeito). ${ }^{77} \mathrm{O}$ acesso era restrito à parte da população devidamente alfabetizada ou que comungasse com os interesses ou necessidades de empregados, sócios, alunos, ou qualquer que fosse a categoria agrupada. De qualquer forma, a presença das bibliotecas e clubes revela um fluxo de leituras e leitores naquela sociedade, permitindo conhecer obras que nem todos tinham, ou nem teriam possibilidade de ter, em casa.

Buscando, principalmente, localizar séries documentais que se caracterizem como "gêneros textuais e (...) materiais impressos que visam incorporar no indivíduo os gestos", pois "entre textos e gestos, as relações são, portanto, estreitas e múltiplas, obrigando a considerar em toda a sua diversidade, as práticas do escrito", ${ }^{78}$ este estudo permite elucidar um pouco mais o quanto as bibliotecas são um aspecto importante da história da leitura e da cultura.

Evidencia-se isso quando se pensa a história da biblioteca em termos metodológicos a partir de pontos de vista diversos, com uma concepção ampla de história da leitura, possível graças a "duas abordagens que são necessariamente ligadas: reconstruir a diversidade de leituras mais antigas a partir de seus vestígios múltiplos e esparsos, e identificar as estratégias através das quais autoridades e editores tentaram impor uma ortodoxia ou uma leitura autorizada do texto" ${ }^{79} \mathrm{~A}$ biblioteca como instituição fornece um locus privilegiado para tais ações, ao mesmo tempo que sua instituição (como rito) "é um ato de comunicação de uma espécie particular: ele notifica a alguém sua identidade", ${ }^{80}$ que define, pela gestualidade, acesso e comportamentos controlados, o outro da civilização.

77 "Veneração é o respeito profundo e submisso". SILVA, A. de M. Diccionario da língua portugueza t.II, p.722. "Respeito: (...) veneração a alguém, consideração, attenção.". ROQUETTE, F. S. Diccionario da língua portuguesa, p.654.

78 CHARTIER, R. Leituras e leitores, p.12.

79 CHARTIER, Roger. Textos, impressões e leituras, p.215

80 BOURDIEU, P. A economia das trocas lingüísticas, p.101. 